INDULTO - EFEITO SÔBRE A PENA ACCESSÓRIA DE DEMISSÃO - READMISSÃO

- Ainda que o indulto não atinja a pena accessória de demissão de cargo, pode o indultado pleitear a readmissão e o poder competente é livre de fazê-lo.

\title{
MINISTERIO DA JUSTIÇA E NEGÓCIOS INTERIORES
}

\section{PROCESSO N. ${ }^{\circ} 1.128-44$}

Recurso de Carlos Gentil de Araújo do ato que o demitiu do cargo de oficial administrativo, classe 71, que ocupava na Prefeitura do Distrito Federal.

Aprovada, em 18-5-45, exposição de motivos que conciui:

Senhor Presidente, entendo, também, de acôrdo com o parecer do relator na CENE, que o recurso não merece provimento.

\section{COMENTÁRIO}

\section{INDULTO E PENA ACCESSÓRIA}

A perda de função pública eletiva ou de nomeação é pena accessória, em que incorre o condenado a pena privativa de liberdade por crime cometido com abuso de poder ou violação de dever inerente a função pública, ou por outro crime, a pena de reclusão por mais de dois anos ou de detenção por mais de quatro (Código Penal, arts. 67, n. ${ }^{\circ}$ I, e 68 , ns. I e II).

2. Num regime de repartição de poderes e de funções, como é o nosso, ao juiz não cabe a lavratura dos atos de demissão. Ante a comunicação da sentença condenatória, cumpre aos agentes do Executivo ou do Legislativo, quando fôr caso, lavrar os atos complementares da perda da função, como executores da lei e das decisões judiciais na esfera de sua competência. 
Entretanto, nada impede que o recorrente seja indultado da pena accessória de demissão do cargo que exercia. Aliás, independentemente dêsse ato, é possivel a sua readmissão, e o poder competente é livre de fazê-lo, tanto mais quanto nada foi alegado a respeito da situação funcional do requerente, sendo certo que já ultrapassou o limite de idade para iniciar a vida noutro serviço.

Aproveito a oportunidade para renovar a Vossa Excelência os protestos do meu mais profundo respeito - Agamenon Magalhães.

PARECER DA C.E.N.E;

Carlos Gentil de Araújo, ex-funcionário da Prefeitura do Distrito Federal, em memorial dirigido ao Senhor Presidente da República solicitou revisäo do processo que recebeu no Protocolo do Palácio do Catete o n. $0^{\circ} 839-43$, e qué passou, depois, a ter o n. $0^{\circ} \mathbf{3 0 . 9 9 9 - 4 3}$
- S.P.R. (fls. 4 - proc. n. $7,222-44$ - P.D.F.).

Não fica êste procedimento adstrito a qualquer restrição hierárquica. Basta que a autoridade judiciária seja a competente para que seu vereditum com trânsito em julgado obrigue a todos os responsáveis pelos atos complementares, sejam agentes federais, estaduais ou municipais.

3. A punibilidade, porém, extingue-se pela concessão da graça ou indulto (Código Penal, art. 108, II), que, a partir da Constituição de 1934 (art. 56, n..$^{\circ}$; Constituição de 1937, art. 75, f; Lei Const. n. ${ }^{\circ}$, art. $74, n$ ), é ato da competência do Presidente da República, excluídos 'os Governadores e Presidentes de Estados, como acontecia no regime de $91 .^{1}$

Relativamente aos efeitos do indulto ou graça sôbre as penas accessórias, silenciou o Código Penal de 40, salvo nos casos de prescrição (art. 118, parágrafo único).

No direito anterior, havia regra expressa a respeito:

"As incapacidades pronunciadas pela condenação cessam em conseqüência do indulto de graça" (Código Penal de 90, art. 74).

Tais incapacidades, segundo os comentadores, eram as mencionadas no art. 55, as de exercício de funções, empregos e ofícios públicos," assim como as resultantes da privação do exercício de uma arte ou profissão.?

\footnotetext{
1 "Na vigência da Constituição de 91 (art. 48, n. $0^{\circ}$ ), a competência privativa da Presidento da Repúblicá pâiá comutaçäo ou perdão das penas criminais era limitada tăo sòmente aos casos em que os crimes fóssem sujeitos à jurisđição federal.

Nesses têrmos, desde que o julgamento fôsse da competência das Justiças estaduais, as penas impostas por essas justiças poderiam ser indultadas ou comutadas pelo Presidente ou Governador do Estado, quando a Constituicão estadual the conferisse essa competência, êsse poder ot essa prerrogativa" (Francisco Campos, Direito Constitucional, ed. Rev.
Forense, pág. 233).
}

2 Galdino Stougira, Dircito Penal Brasileiro, vol I, n. 480

3 Cōsta e Silva, Cód. Penal Com, vol II, 1938, pág 361 


\section{Alegou o interessado:}

a) que é sempre lícito a quem governa ou administra fazer a revisão de processos já solucionados, desde que considere ter havido qualquer êrro ou injustiça no julgamento (fis. 4 - proc. n. $.^{0} .222-44$ - P.D.F.);

b) que a revisão de processos tem sido feita, quer pela Presidência da República, quer pelos Ministérios, quer pela Prefeitura (fls. $4-$ proc n. $7.222-44-$ P.D.F.);

c) que depois de 1930 chegou a ser criada uma Comissão Revisora (fls. 4 - processo n. $7.222-44-$ P.D.F.);

d) que sempre foi bom funcionário, assíduo, zeloso, dedicado, đisciplinado, sem nota alguma que o-pudesse desabonar (fls. 5 - proc. no 7.222-44-P.D.F.);

e) que não é justo, "que ùnicamente pela má atitude de uma senhora (sua espôsa)", também funcionária municipal, viesse a perder o cargo que soube honrar (fls. 5 - processo n.0 7.222-44 - P.D.F.);

f) que desempenhou várias comissōes de confiança e responsabilidade (f1s. 5 . proc. n.0 7.222-44 - P.D.F.);

b) que, quando foi demitido, já estava com 49 anos de idade, e, por conseguinte, êsse ato equivale a uma "condenação perpétua ao desemprêgo". (fls 6 - processo número 7.222-44 - P.D.F.); e

h) que estaria passando fome, se não tivesse o amparo amigo de um seu cunhado, general do Exército (fils. 6 - proc. n. ${ }^{\circ} 7.222-44-$ P.D.F.).

3. A Prefeitura do Distrito Federal, ao encaminhar o memorial, esclareceu.

a) que $o$ interessado era oficial administrativo, classe 71, quando foi demitido, em irenca condenatória do M.M. Juiz de Direito da 1. a Vara Criminal (fls. 2)

b) que, de acôrdo com as informações da Secretaria Geral de Administração, não há motivo paro revisão do processo de demissão, que se baseou no art. $68, n .^{\circ}$ II, do Código Penal (fls. 2);

No direito comparado, encontramos textos que ora prescrevem, ora não, a extinçẫo de penas accessórias. Assim, o Código Penal italiano (art. 174) dispõe que tais penas não são atingidas pelo indulto, salvo menção expressa em contrário, no decreto de concessão. No espanhol de 1870, as inabilitações para o exercício de cargos públicos subsistem no caso de indulto, salvo disposição em contrário. O direito francês é, também, neste sentido, segundo o testemunho de Costa e Silva. ${ }^{4}$

Nada dispondo a respeito a nova codificação brasileira, como se deverá interpretar êsse silêncio?

NELSON HUNGRIA, autor particularmente credenciado para interpretar o Código vigente, afirma:

"A anistia extingue as penas accessórias; e o mesmo efeito têm a graça individual e o indulto, quando totais.

No caso de simples diminuição ou comutação da pena principal, as penas accessórias devem ser reajustadas".

LaERTe Munhoz, professor da Faculdade de Direito do Paraná, é do mesmo sentir:

"As penas accessórias, de um modo geral, extinguem-se nos mesmos casos da extinção da punibilidade, enumerados no art. 108 , salvo quanto à prescrição, porque é expresso no Código (art. 118, pa-

4 Ob. cit., pág. 362.

5 Extinção da punibilidade em face do noro Códißo Penal, em Rev. Forense, vol. 87, página $\mathbf{5 8 5}$. 
c) que no ofício n. $3.744-$ P.R., de $29-11.43$, que encaminhou, devidamente informado, recurso anterior do interessado, o Senhor Presidente da República exarou o des-
pacho: "Arquive-se", (fls. 2); e

d) que não há argumento novo a ser considerado (fls. 2).

4. O Assistente Jurídico desta Comissão, opinando pelo provimento do recurso, pôs em evidència:

a) que o interessado foi condenado pelo M.M. Juiz de Direito da 1. a Vara Criminal, por haver cometido o crime capitulado no art. $294, \$ 1 .^{\circ}$, combinado com o art. 13, da Consolidação das Leis Penais, isto é, tentativa de homicidio (fls. 3);

b) que o Tribunal de Apelação reduziu a pena ao grau médio (fls. 3);

c) que antes de completar 2 anos de prisão, foi o interessado indultado (f1s. 3); đa sua condenação por mais de seiso ainda demitido da "função pública", em conseqüếncia que o indulto cancelara os efeitos anos, requereu a sua volta ao cargo na persuasão de e) que, examinad

que o interessado havia sido estão esquecida, verificou o Prefeito dêsse crime, nos têrmos sido condenađo por tentativa de homicídio e que a pena mínima era de 8 anos de prisão celular (fla (art. 294, $\$ 1 .^{\circ}$, da Consolidação das Leis Penais)

f) que entreta

n. II, do Código Penal, o Prefeito assinou a demissão do interessado, com base no art. 68 ante o princípio de que a retroatividad não pareça o mesmo aplicável à sua situação jurídica, ficia o acusado (fls. 3 e 4);

8) que os efeitos da condenação se subordinam à lei reguladora da ação criminal

h) que o interessado fôra processado e condenado na vigência da Consolidação das Leis Penais, sendo, portanto, os seus dispositivos que devem reger tôda a sua situação ju-
rídica (fls. 4); i) que, assim, só deve ser invocado qualquer dispositivo do Código Penal vigente se
beneficiar o interessado (fls. 5);

j) que a Consolidação das Leis Penais, em seu art. 55, declarava:

"O condenado à pana de prisão celular, maior de seis anos, incorre por tal fato em interdição, cujos efeitos são:

a)

b) perda de todo ofício eletivo, temporário ou vitalício, emprêgo público da

rágrafo único) ser imprescritível a pena accessória imposta na sentença ou resultante de condenação". ${ }^{\circ}$

Opinaram também sôbre o assunto RAUL BARBosa ${ }^{7}$ e GoNCALo Rolemberg LeIte. ${ }^{8}$

4. A questão, entre nós, após o advento do Código, não foi, ao que nos consta, submetida aos tribunais, e continua em aberto.

Parece-me, data venia, que a melhor solução é a inspirada na doutrina italiana, de que nem o indulto nem a graça se refletem nas penas accessórias, salvo disposição expressa em contrário. ${ }^{9}$

$\mathrm{Na}$ ausência de texto expresso de lei, a conclusão há de basear-se na natureza do instituto.

6 Das penas accessórias, in Rev. Fosense, vol. 94, pág. 465.

7 Extinção da punibilidade, in Anais do 1.० Cong. Nac. do M. Público, vol. 3, pág. 409. 8 A graça, o indulto, a anistia e a reabilitação, in Anais do $10^{\circ}$ Cong. Nac. do $M$. Pú-
blico, vol. 8 , pág. 337 .

9 "Nè l'indulto, nè la ǵrazia si reflettono sulle pene accessoire, le quali possono dîtentare oggetto, in quanto il decreto lo dichiàri, nè sugli altri effetti penali." EUGÊNIO FLORIAN, Trat, de Dit. Pen., part. ger., vol. $2 .^{\circ}$, n. ${ }^{\circ} 926$, p. 1.132, 4." ed., 1934. 
Nação ou dos Estados e das respectivas vantagens e vencimentos;

c)

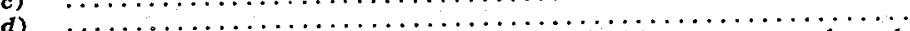

Parágrafo único - Sempre que a lei aplicar além da pena corporal, a de privação de exercício de alguma parte ou profissão, esta pena só produzirá os seus efeitos depois de cumprida a pena corporal (fls. 5);

1) que, dos dispositivos enunciados, se deđuz que a perda do "emprêgo público"? đecorre da sentença condenatória que impuser ao delinqüente pena superior a seis anos (fís. 6);

m) que desde que a pena seja inferior a ésse tempo, o condenado, depois de cumprida a sentença, "voltará" ao exercicio do seu cargo (fls. 6);

n) que a Consolidação das Leis Penais estabelecia em seu art. 71:

"A ação penal extingue-se:

1. pela morte do criminoso;

2.0 pela anistia do Congresso

3.0 pelo perdão do ofendido;

4.0 pela prescrição";

e no art. 72 :

"A condenação extingue-se por estas mesmas causas e mais:

1. pelo cumprimento da sentença;

2. pelo indulto do poder competente;

3." pela reabilitação" (fls. 6);

o) que os arts. 74, 75 e 76 esclareciam:

"As incapacidades pronunciadas pela condenação cessam em consequêencia do inculto de graça".

"A anistia extingue todos os efeitos da pena e pỏe perpétuo silêncio ao processo."

"A anistia e remissão das penas; por indulto de graça, não eximem o agraciado de satisfazer a indenizaçäo do dano" (fls. 6); p) que da apreciação dêsses dispositivos legais se infere que o indulto está equipa-
rána satisfazer a indenização do dano"' (fts. 6);

Na definição de Costa e Silva, indulto é o ato pelo qual o poder público competente faz cessar, no todo ou em parte, os efeitos de uma condenaȩão penal, imposta 2 uma oll mais pessoas. ${ }^{10}$

E doutrina corrente, que o tratadista acolhe quando usa da expressão "no todo ou em parte", que o indulto e a graça são favores que podem e devem ser medidos. No ato da concessão, o Chefe do Estado traça os limites de sua amplitude, tendo em consideração as circunstâncias e as peculiaridades de cada caso.

"E lícito ao Presidente da República, concedendo o indulto, torná-lo dependente de têrmo ou condição"? indaga o autor citado, para responder: - "A resposta deve ser afirmativa". 11

O único árbitro da extensão do favor, isto é, se o ato deve, ou não, abranger as penas accessórias, deve ser o Presidente da Repú-

10 Cód. Penal Com., vol. II, 1938, pág. 352.

11. Costa e Silva, ob. cit., vol. II, pág. 356. 
q) que não se compreence, pois, que haja firmeza jurídica na demissão do interessado após o indulto de graça, conredido pelo Presidente da República, "que acumulà, nạs suas atribuições, os poderes executivo e legislativo da República" (f1s: 6 e 7);

r) que não se afigura procedente o argumento "de que a perca de cargo é uma consequiência da ação penal e se ciecorre dela a condenação, o indulto, apenas, extingue o efeito
físico da pena" (f1s. 7); e

s) que, de acôrdo com o axioma jurídico de que — onde a lei não distingue a ninguém e licito distinguir - não se pode negar ao indulto a fôrça de extinguir os efeitos da condenação, com exceção, apenas, "à testrição expressamente feita pelo art. 76 da Consolidação das Leis Penais, de satisfazer o agraciado a reparação do dano e ainda em face do expresso
no art. 74 da mesma Consolidação"' (fls. 7 ).

5. Examinando o assunto, verifica-se:

a) que a perda do cargo público constituía, ao tempo em que o interessado praticou - referido crime, em que foi processado e condenado de acôrdo com a Consolidação das Leis Penais, imposição inerente à pena de prisão celular resultante de condenação superior
a 6 anos;

b) que não procede a afirmativa de que o indulto, quanto aos seus efeitos jurídicos, se equipara à anistia, porquanto ambos os institutos apresentam características distintas, con-
fcrme reconhecem os tratadistas;

c) que o decreto de indulto está redigido nos seguintes têrmos:

blica. Se silencia a propósito de tais penas, é porque não quis extinguí-las .

Os efeitos da condenação só se devem considerar apagados na medida que forem mencionados no decreto de concessão. ${ }^{12}$

Esta, foi, aliás, a tese esposada pela Administração, conforme a decisão supra.

INão só o Sr. Ministro da Justiça, como o Exm. ${ }^{\circ}$ Senhor Presidente da República, aceitaram o parecer do relator no sentido de se considerar excluída do indulto a pena accessória.

E por assim concluir foi que o Sr. Ministro afirmou: "nada impede que o recorrente seja indultado da pena accessória de demissão do cargo que exercia". Evidentemente, o que ficou na dependência de ato posterior é o que não foi contemplado no anterior.

\section{A questão é, porém, complexa, e não cremos esteja encer-} rada com êste precedente.

A adoção de uma regra geral por parte do órgão incumbido de informar os papéis relativos ao indulto e encaminhá-los ao Excelentíssimo Senhor Presidente da República poderia evitar futuras controvérsias, como scja a de fazer menção expressa em todos os decretos sôbre se atingem, ou não, as penas accessórias .

12 Com referência à indenização à vítima do crime e às penas pecuniárias, dispôs o Decreto-lei n.o 1.726, de 1-11-39, que regulou a incidêricia, arrecadação e fiscalizaçấo do sêlo penitenciário, no art. 17, que : "Salvo declaração expressa no decreto que o conceder o indulto integral ou parcial da pena detentiva não isenta o indultado do pagamento da indenização à vítima do crime, nem dos demais pagamentos da pena pecuniária". 
Indultar :

Usando da atribuição que the confere o art. 75 , letra $f$, da Constituição:

Atendendo a que o sentenciado Carlos Gentil de Araújo já cumpriu quase 2 anos da pena de 10 anos e 2 meses de prisão com trabalho, grau médio do art. $294, \S 1 .^{\circ}$, combinado com o art. 13 da Consolidação das Leis Penais, que the foi imposta pelo Tribumal de Apelação desta Capital, o referido sentenciado do resto da mencionada pena' (Diário Oficial de 4-3-43, pág. 3.165);

d) que o indulto tem os efeitos estabelecidos no decreto em que fôr concedido;

e) que, no caso em apréço, o interessado foi indultado do resto da pera de 10 anos e 2 meses de prisão, com trabalho, grau médio do art. 294, $\S 1 . \%$, combinado com o art. 13 da Consolidaçâo das Leis Penais;

f) que a intenção de limitar os efeitos de benefício a liberdade física do condenado transparece claramente do decreto do indulto;

B) que, ainda, se assił não fósse, o único árbitro da extensão do favor, isto é, se o to devia ou não abranger as "penas accessórias" - O Senhor Presidente da República já se manifestou pela interpretação restritiva, determinando o arquivamento de um pedido do interessado, que versava, precisamente, êste aspecto da controvérsia (Desp. de 29-11-43, exarado na E.M. do Prefeito, pub. em 4-12-43);

h) que, embora a revisão processual, na esfera administrativa, seja sempre possível e encontre precedentes, no caso em estudo, ela não se justifica, como bem acentuou a Prefeitura, dada a legitimidade da demissão do interessado;

i) que, de fato, como salientou o Assistente Jurídico desta Comissão, o ato de demissão, com base no art. 68, n. II, do Código Penal, encerra uma impropriedade, pois a condenação obedeceu aos preceitos da Consolidação das Leis Penais, então vigente;

j) que, entretanto, a irregularidade apontada não invalida 0 ato em si, pois a demissão do interessado, como pena accessória, constitui ato legítimo, sob todos os aspectos.

6. Nestas condições, opinando pelo indeferimento do pedido, sou pelo encaminhamento do processo à Prefeitura do Distrito Federal, para que seja providenciada a retificaçäo do decreto de demissão do interessado. Estaduais.

Em 7-3-45. - Luís Simões Lopes, Membro da Comissão de Estudos dos Negócios

Com êste expediente, advertida a autoridade concedente de que o indultado ficou privado do cargo ou função pública em virtude da condenação, de pronto poderia optar pela forma ampla ou pela restrita, atendendo às peculiaridades de cada caso.

Há, ainda, a considerar a circunstância de refletir o ato de indulto, de competência federal, nos quadros dos servidores estaduais e municipais.

6. Finalmente, convém esclarecer que mesmo o indulto amplo "não extingue o delito", e que "o indultado continua a ser um condenado", conforme a lição de Costa e Silva. ${ }^{13}$ Não é possível, portanto, falar em reintegração, que pressupóe ato de demissão ilegal e nulo e como tal proclamado em definitiva instância. Sòmente a readmissão, a juizo do Govêrno, como, aliás, já opinou o D.A.S.P. em outra oportunidade, ${ }^{14}$ se deve considerar.

\section{Carlos Medeiros Silva}

13 Costa $z$ Silva, ob. cit., pág. 356.

14 D.O. de 30-4-41, Jurisprudência Administrativa, vol. VI, pág. 656. 